\title{
Recent Discoveries in Mexico and Guatemala
}

GXCAVATIONS on Monte Alban in the State of Oaxaca, Mexico, the site on which the rich grave treasure of gold and other ormaments was found in January of last year, were resumed at the end of October by Señor Alfonso Caso on an extended scale immediately the decision of the Supreme Court on the question of State jurisdiction over antiquities had been made known. By the end of November, according to progress reports for which we are indebted to Science Service (Washington, D.C.), some interesting results had been achieved, although in certain respects their exact bearing at present remains obscure.

Among the more striking of the finds is a tomb remarkable for its small size. It is less than $2 \mathrm{ft}$. wide, and not $7 \mathrm{ft}$. in length. It is lined with stone, and the door was closed with a corn-grinding stone. Immediately within the doorway was a headless skeleton; while at the back part of the tomb were a heap of human bones, four large dishes and animal bones. In addition, it contained two incense burners, two greenstone axes, jade, and a bird's skull. The most noteworthy feature of the discovery, however, is that on the front of the tomb, underneath the lintel and on the door jambs, as well as on the stone floor at the entrance, are paintings in red, green and yellow. If the culture is Zapotec, these are the first Zapotecan paintings to be recorded. It is concluded that they deal with the calendar, representing year- and day-names in the Mayan or Zapotecan calendar.

Outside the tomb were found a number of objects in pottery which have all the appearance of votive offerings-objects resembling ears of corn, human hands, a tiger's foot, etc., with the image of a corn god and another deity not identified.

Another find of a singular character is a series of human figures in eccentric postures. These were found as a border or frieze at the base of a stepped pyramid, or temple, which is now being excavated. This is known as the 'Temple of the Dancers' from figures on the walls of a stone-lined tunnel in the mound, which was penetrated a few years ago. Of the figures which have now been brought to light, some are shown as crawling or swimming, while others lie on their backs. One holds an object at his lips as if drinking. Others appear to be deformed. It is thought that the figures may represent a priestly orgiastic fertility rite such as was described by early Spanish writers. This view is supported by the emphasis laid on the sex of the figures-normally the priests were expected to be celibate.

A second tomb of almost identical dimensions, with a roof shaped as an inverted $V$, has been discovered. It contained parts of two skeletons with funerary furniture, possibly secondary interments.

It remains only to describe what is up to the present the most remarkable feature of the site, of which the purpose is at present obscure. This is a series of stone-lined tunnels too small to serve as emergency passages, as was at first suggested, and not apparently intended for drainage. The first was discovered at the close of last season's work, but its exploration left until this year. When it was entered on the resumption of work, it was found to be so small-20 in, high by $25 \mathrm{in}$. wide-that the explorers had to proceed stretched at full length on their backs and work their way along by elbows and toes. At a distance of $195 \mathrm{ft}$. in the tunnel a skeleton was found, accompanied by an incense burner, funerary urns and ornaments of jade, stone and turquoise as well as a few pearls. Some yards further the tunnel was found to be blocked and had to be entered again by a shaft sunk from the surface $25 \mathrm{ft}$. above for the purpose. A second skeleton was found $320 \mathrm{ft}$. from the entrance, just before the tunnel terminated at the side of the north terrace. It was found that a number of even smaller tunnels, not more than a foot high, led into the larger tunnel. Of these one had tiny steps leading down to it.

Two further tunnels of similar character to the first were found, but packed with earth or clay. Finally, a complex of miniature tunnels was found to the east of the famous treasure tomb. All are stonelined and some are less than a foot high. Some, but not all, have the inverted $V$ roof. The application of a smoke test revealed a number of unexpected exits.

The Carnegie Institution of Washington has now issued particulars of the important discovery of Mayan pottery made in 1931 at Uaxactun, Guatemala, by one of its expeditions (News Service Bull., vol. 2, No. 36). This discovery was remarkable not only as an indication of the high standard attained in ceramics by the Maya at an early date, but also as the first example of a Maya date inscribed on any material other than stone or stucco.

The pottery was discovered in two burial vaults at the top of a pyramid in Group $A$ in the so-called acropolis. This pyramid is the third in a series of five built one on top of the other in accordance with Maya practice.

Vault 1 is $7 \frac{1}{2} \mathrm{ft}$. long, $1 \frac{3}{4} \mathrm{ft}$. wide and $2 \mathrm{ft}$. high, with walls of roughly-cut stone and six limestone slabs superimposed, as a cover. It contained the skeleton of an adult male with funerary furniture, offerings, ornaments, etc., among which was a remarkable polychrome vase. The second vault was approximately of the same stze, though slightly shorter. It contained the remains of several skeletons and seven polychrome vases. Between the two vaults were two more polychrome bowls which had probably accompanied a secondary burial.

Of the polychrome vessels, which are painted in red, orange and black, all are sufficiently noteworthy ; but three in particular stand out. A shallow bowl 14 in. in diameter, a flanged tripod dish and the cylindrical jar found in the first vault. All are painted with representations of one or more human figures. The most elaborate shows among other figures a naked man hanging head downward with two jaguars apparently about to spring on him. $\mathrm{He}$ is evidently the victim of a human sacrifice. The design is divided into two fields by the figure of a serpent across the vessel. The scene shown on the cylindrical jar is complicated; but it is thought to represent the reception of a deputation or embassy by a dignitary who is seated on a dais. The date, to which reference is made above, is shown in sixteen calendrical glyphs which have been interpreted by Dr. S. P. Morley, after a slight emendation, as giving the date 120 B.C. or A.D. 140 according to the chronological system employed in interpretation. This, however, is not the date of the vase; the painting is taken to be a record of an event long past. 